\title{
BLOOD ADRENOCORTICOTROPHIC HORMONE AND PLASMA CORTICOSTEROIDS IN MEN EXPOSED TO ADVERSE ENVIRONMENTAL CONDITIONS ${ }^{1,2}$
}

\author{
BY HENRY B. HALE, GEORGE SAYERS, KATHERINE L. SYDNOR, \\ MAX L. SWEAT, 4 AND DONALD D. VAN FOSSAN \\ (From the Department of Physiology-Biophysics, School of Aviation Medicine, USAF, \\ Randolph Air Force Base, Texas, and the Department of Physiology, \\ Western Reserve University School of Medicine, Cleveland, Ohio)
}

(Submitted for publication March 4, 1957; accepted August 14, 1957)

Electroshock (2), surgical trauma (3), accidental trauma and acute illness (4) are associated with elevations in plasma corticosteroids in man. It was of considerable interest to extend these observations to include adverse environmental conditions. Metabolic and hematologic changes similar to those resulting from the administration of adrenocorticotrophic hormone (ACTH) or corticosteroids have been reported to occur in human subjects experiencing hypoxia (5-7). In the present investigation blood ACTH and plasma corticosteroid concentrations were determined in subjects experiencing hypoxia, alone or in combination with heat. The influence of the adverse environmental conditions on the physiological wellbeing of the subjects was evaluated by measurement of changes in heart rate, respiration, body temperature, and urinary excretion of certain metabolites.

\section{METHODS}

Experiment 1. Short exposures; hypoxia induced by inhalation of a gas mixture low in oxygen. Seventy-nine healthy men, 18 to 35 years of age, served as subjects, each man serving on only one occasion. The subjects were divided into the following groups: (a) control, (b) hypoxia, (c) heat, and (d) hypoxia plus heat. During control and hypoxia tests, the environmental temperature

\footnotetext{
1 Supported in part by funds from the United States Air Force under Contract No. AF 18(600)-621, monitored by the School of Aviation Medicine, USAF, Randolph Air Force Base, Texas.

2 Part of this work was reported orally at the 1954 meeting of the Federated Societies for Experimental Biology (1), and issued as School of Aviation Medicine, USAF, Report 57-55, 1957.

3 Present address: The Ben May Laboratory for Cancer Research, University of Chicago, Chicago, Ill.

4 Present address: Department of Obstetrics and Gynecology, College of Medicine, University of Utah, Salt Lake City, Utah.
}

was $27^{\circ} \mathrm{C}$., relative humidity 50 per cent, and the subjects breathed by mask either room air or an oxygennitrogen mixture which, at ground level barometric pressure $(750 \mathrm{~mm} . \mathbf{H g}$ ), provided $100 \mathrm{~mm}$. $\mathrm{Hg}$ inspired oxygen tension. Exposure to heat was accomplished in a cylindrical metal chamber in which air temperature (dry bulb) averaged $49^{\circ} \mathrm{C}$., and the wall temperature $52^{\circ} \mathrm{C}$., with relative humidity 18 to 20 per cent; under these conditions, one group breathed air and a second group the oxygen-nitrogen mixture.

After 2, 15 or 45 minutes of exposure, $20 \mathrm{ml}$. of blood were drawn from an antecubital vein into a heparinized syringe for corticosteroid analyses, then $200 \mathrm{ml}$. were drawn directly into glacial acetic acid for ACTH analysis. Plasma corticosteroids were determined by the method of Sweat (8). Blood was processed by the oxycellulose technique (9) and assayed for ACTH in hypophysectomized rats by the adrenal ascorbic acid depletion method. (10). A dose of eluate equivalent to $40 \mathrm{ml}$. blood was injected into each of five test rats. An estimate of the concentration of ACTH was based on the average response of the test rats to doses of unknown and the responses induced by the administration of 1.0 and 0.25 milliunits (mU) U.S.P. ACTH per $100 \mathrm{Gm}$. rat on the same day. As an additional control, five hypophysectomized rats were injected with 0.9 per cent $\mathrm{NaCl}$ solution in each assay.

Experiment 2. Three hour exposure; hypoxia induced by decompression in heated chamber. Five male subjects, 31 to 42 years of age, wearing shorts, were decompressed to the barometric pressure level equivalent to 14,000 feet altitude (total pressure, $446 \mathrm{~mm}$. $\mathrm{Hg}$; oxygen tension, $95 \mathrm{~mm} . \mathrm{Hg}$ ) in a chamber in which the air and wall temperatures were held at $51^{\circ} \mathrm{C}$. and relative humidity at 13 per cent. Air was circulated through the chamber at a constant rate, and the subjects remained seated throughout the exposure. Cardiovascular, respiratory, and body temperature determinations were made periodically, and $20 \mathrm{ml}$. blood samples (venous) for corticosteroid, hematocrit, sodium, and potassium determinations were drawn immediately before the exposure, at the end of the second and third hours of exposure, and one hour after exposure. Urine samples collected one hour after exposure were analyzed by standard methods (11) for uric acid, creatinine, sodium, and potassium, and comparison was made with samples obtained at the same 
time on the previous day; on both occasions the urine samples represented a four hour accumulation.

Experiment 3. Two hour exposure; hypoxia induced by decompression in heated chamber. Eight male subjects, 18 to 23 years of age, were exposed in the same manner as in Experiment 2. Results are presented separately because the condition of the subjects made it necessary to terminate the exposure one hour earlier than had been intended. Rectal temperature, heart rate, and sweating rate determinations were made, and $20 \mathrm{ml}$. of blood were drawn just prior to exposure, at the end of two hours' exposure, and one hour postexposure.

\section{RESULTS}

\section{Experiment 1}

Blood samples from 54 of the 79 subjects were assayed for ACTH. Except for two subjects (one a control, and the other a heat-exposed subject), the ACTH titer was uniformly less than $0.5 \mathrm{mU}$ per $100 \mathrm{ml}$. blood. The blood ACTH of the exceptional control subject was estimated to be 2 $\mathrm{mU}$ and that of the heat-exposed subject to be 0.5 $\mathrm{mU}$ per $100 \mathrm{ml}$. blood. No significant differences in the concentrations of 17-hydroxycorticosterone or of corticosterone-like steroids were found between the different groups of subjects. Data for 62 experimental subjects and for a group of 9 subjects who were not subjected to experimental procedures are summarized in Table I.

Changes in heart rate, systemic blood pressure, respiratory minute volume, and respiratory quotient tended to become maximal after approximately 15 minutes in the hypoxic subjects, whether at room temperature or in the hot chamber, and to remain fairly steady thereafter. The factor of heat had an intensifying effect on the response to hypoxia. To illustrate, heart rate, on the average, during hypoxia alone was not elevated to the same extent as with hypoxia plus heat, while hypoxia combined with heat induced an abrupt elevation in heart rate in contrast to a progressive increase with heat alone.

\section{Experiment 2}

The pre-exposure value for 17-hydroxycorticosterone in this group of five subjects was not significantly different from the control values obtained in Experiment 1 (Table II). The mean change noted at the end of two hours of exposure was not significant. All subjects exhibited in-
TABLE I

Plasma corticosteroids in relation to hypoxia and heat stress (experiment 1)

\begin{tabular}{|c|c|c|c|}
\hline Treatment & $\begin{array}{c}\text { No. of } \\
\text { eubjects }\end{array}$ & $\begin{array}{l}\text { 17.hydroxy- } \\
\text { corticosterone } \\
\text { (us / / } 100 \text { ml. } \\
\text { plasma) }\end{array}$ & $\begin{array}{c}\text { Corticosterone- } \\
\text { like steroidds } \\
\text { (us } / 100 \mathrm{ml} \text {. } \\
\text { plasma) }\end{array}$ \\
\hline Control $^{*}$ & 9 & $10.8=$ & $3.7 \pm 0.4$ \\
\hline $\begin{array}{l}\text { Two-minute test } \\
\text { Hypoxia }\end{array}$ & 6 & $8.8 \pm 1.3$ & $4.2 \pm 1.0$ \\
\hline $\begin{array}{l}\text { Fifteen-minute test } \\
\text { Control } \\
\text { Heat } \\
\text { Hypoxia } \\
\text { Hypoxia plus heat }\end{array}$ & $\begin{array}{l}6 \\
8 \\
6 \\
8\end{array}$ & $\begin{array}{l}11.2 \pm 0.4 \\
10.0 \pm 0.8 \\
13.3 \pm 2.4 \\
11.3 \pm 1.8\end{array}$ & $\begin{array}{l}4.8 \pm 1.1 \\
5.8 \pm 1.0 \\
5.8 \pm 1.5 \\
5.6 \pm 0.8\end{array}$ \\
\hline $\begin{array}{l}\text { Forty-five minute tes } \\
\text { Control } \\
\text { Heat } \\
\text { Hypoxia } \\
\text { Hypoxia plus heat }\end{array}$ & $\begin{array}{l}6 \\
8 \\
6 \\
8\end{array}$ & $\begin{array}{l}10.4 \pm 1.6 \\
11.7 \pm 1.3 \\
14.2 \pm 3.2 \\
12.6 \pm 1.3\end{array}$ & $\begin{array}{l}5.8 \pm 1.8 \\
4.6 \pm 0.8 \\
5.1 \pm 0.8 \\
5.9 \pm 0.3\end{array}$ \\
\hline
\end{tabular}

* Nonexperimental subjects, 19 samples.

$\dagger$ Mean and standard error of the mean.

creases in plasma concentration of 17-hydroxycorticosterone at three hours, although the increases for two of the subjects are of doubtful significance. When analyzed on the basis of the gain above the pre-exposure levels, the mean change was statistically significant $(>0.01,<$ 0.02 ). After a one hour recovery period, the average concentration had fallen to a level which was not significantly different from the pre-exposure level. Although showing the same tendency as 17-hydroxycorticosterone, the plasma concentration of corticosterone-like steroids was not significantly altered at any time. Hematocrit determinations did not indicate any significant degree of hemoconcentration.

As for the physiologic state, at the end of the exposure heart rates ranged from 105 and 125 beats per minute, oral temperatures from $37.4^{\circ}$ to $38.0^{\circ} \mathrm{C}$., mean skin temperatures (average of five equal areas) from $37.7^{\circ}$ to $39.4^{\circ} \mathrm{C}$., and ventilation (BTPS) from 4.7 to 27.6 liters per minute. Sweating rates (nude weight loss) ranged from 0.28 to $0.69 \mathrm{Kg}$. per $\mathrm{M}^{2}$ per hour. One subject became incapacitated during the third hour, experiencing bradycardia, but he did not lose consciousness. Symptoms of hypoxia (cyanosis, euphoria, mental confusion, personality change), which were unusual for this altitude, were noted in all subjects. At the end of the one hour recovery period, heart rates and oral temperatures 
TABLE II

Plasma corticosteroids in relation to decompression at high ambient temperature

\begin{tabular}{|c|c|c|c|}
\hline & $\begin{array}{l}\text { 17-hydroxycorticosterone } \\
\text { (us./100 ml. plasma) }\end{array}$ & $\begin{array}{l}\text { Corticosterone-like } \\
\text { steroids } \\
\text { (us./100 ml. plasma) }\end{array}$ & $\begin{array}{l}\text { Hematocrit } \\
(\%)\end{array}$ \\
\hline \multicolumn{4}{|c|}{ Experiment 2 (5 subjects) * } \\
\hline $\begin{array}{l}\text { Pre-exposure } \\
\text { Two hrs. exposure }\end{array}$ & \multirow{3}{*}{$\begin{array}{r}9.5 \pm 0.9 \dagger \\
10.3 \pm 2.0 \\
(+0.8 \pm 2.0) \\
15.3 \pm 2.2 \\
(+5.8 \pm 1.4) \\
11.1 \pm 1.4 \\
(+1.6 \pm 1.6)\end{array}$} & $\begin{array}{l}4.6 \pm 0.9 \\
5.0 \pm 0.9\end{array}$ & $\begin{array}{l}43.8 \pm 1.4 \\
46.0 \pm 1.2\end{array}$ \\
\hline & & $5.8 \pm 0.6$ & $45.0 \pm 0.7$ \\
\hline One hr. postexposure & & $3.8 \pm 0.3$ & $44.8 \pm 1.3$ \\
\hline \multicolumn{4}{|c|}{ Experiment 3 (8 subjects) * } \\
\hline $\begin{array}{l}\text { Pre-exposure } \\
\text { Two hrs. exposure } \\
\text { One hr. postexposure }\end{array}$ & $\begin{array}{l}10.2 \pm 1.3 \\
16.4 \pm 3.4 \\
13.7 \pm 2.8\end{array}$ & $\begin{array}{l}5.7 \pm 1.2 \\
7.8 \pm 1.8 \\
7.2 \pm 1.1\end{array}$ & $\begin{array}{l}45.8 \pm 0.9 \\
45.5 \pm 1.0 \\
45.1 \pm 0.8\end{array}$ \\
\hline
\end{tabular}

* In Experiment 2 the barometric pressure is $446 \mathrm{~mm}$. $\mathrm{Hg}$; air and wall temperatures, $51^{\circ} \mathrm{C}$.; relative humidity, 13 per cent. In Experiment 3 the barometric pressure is $446 \mathrm{~mm}$. $\mathrm{Hg}$; air temperature, $48^{\circ} \mathrm{C}$.; wall temperature, $50^{\circ} \mathrm{C}$.; relative humidity, 22 per cent.

$\dagger$ Mean and standard error of the mean; values in parentheses indicate mean increase above pre-exposure level along with standard error of the mean increase.

were not completely restored to the pre-exposure levels. Although there were no significant changes in plasma $\mathrm{Na}, \mathrm{K}$, or the $\mathrm{Na} / \mathrm{K}$ ratio, changes in urine volume and in the output of certain urinary constituents clearly reflected the influence of the high temperature. Urine output on this occasion averaged $27 \mathrm{ml}$. per hour, whereas on the previous afternoon it had averaged $60 \mathrm{ml}$. per hour; the urinary uric acid/creatinine and $\mathrm{Na} / \mathrm{K}$ ratios fell from 0.275 to 0.202 and from 1.55 to 0.55 , respectively. The changes in these ratios were significant $(p<0.02$ for the former, and $p<0.01$ for the latter).

\section{Experiment 3}

The pre-exposure value for 17-hydroxycorticosterone for this group was not significantly different from control values in Experiments 1 and 2 (Table II). Although five of the eight subjects exhibited increases in plasma 17-hydroxycorticosterone levels after two hours of exposure, the average of the individual changes $(+6.2 \pm 2.8)$ was not significantly different from zero. Corticosterone-like steroids also were not changed significantly. In four of the eight cases, values for 17-hydroxycorticosterone were elevated after a one hour recovery period when compared with pre-exposure levels. Hematocrit values were not changed significantly.

Subjectively, this group of subjects found the exposure to be a distressing experience. Two subjects became incapacitated; in both cases heart rate was approaching 140 beats per minute, a rate which, for inactive subjects, is considered a critical limit. When ranked on the basis of an index of physiologic strain (12), which evaluates in quantitative terms the effects of the thermal environment, the subjects with the three highest strain values exhibited increases in 17-hydroxycorticosterone in the range +5.2 to $+18.9 \mu \mathrm{g}$. per $100 \mathrm{ml}$. plasma. Of the remaining subjects, two were unable to remain in the chamber for two hours, and the strain index was not computed; the other three had the lowest strain values, and for these subjects the changes in the steroid concentration were in the range -1.0 to $+6.1 \mu \mathrm{g}$.

\section{DISCUSSION}

The results confirm previous observations (13) that blood of normal male subjects contains less than $0.5 \mathrm{mU}$ ACTH per $100 \mathrm{ml}$., and the observations of Paris, Upson, Sprague, Salassa, and Albert (14), who have been unable to detect ACTH in the blood of normal subjects. The estimate is based on the fact that $0.25 \mathrm{mU}$ ACTH induces a response in test rats, and the fact that the equivalent of $40 \mathrm{ml}$. of blood fails to induce a significant depletion of adrenal ascorbic acid. The relatively high recovery of ACTH by the oxycellulose method (10) indicates that failure to 
detect the hormone in blood is not due to loss incurred during processing.

It is to be emphasized that our failure to detect ACTH in the blood of subjects exposed to hypoxia does not rule out increased rate of release of ACTH from the adenohypophysis. Of interest in this connection are the observations of Thorn, Jenkins, and Laidlaw (7) that a very small dose of ACTH given by constant intravenous infusion ( 0.25 unit per hour) induces significant increases in urinary excretion of corticosteroid metabolites. This rate of infusion of ACTH would not be expected to increase blood ACTH to a level detectable by our method. More sensitive methods for the analysis of blood ACTH must be developed before we can clarify the problem of ACTH release in response to noxious stimuli in man.

Franksson and Gemzell (15) have presented data which they interpret to mean that the apprehension immediately prior to surgery is associated with an increase in peripheral plasma corticosteroid levels as measured by the method of Nelson and Samuels (16). In the present experiments subjects were noticeably apprehensive, yet the pre-exposure levels did not differ from those of untreated controls.

The fact that the plasma corticosteroids did not increase in concentration during the first $45 \mathrm{~min}$ utes of exposure to hypoxia cannot be explained on the basis of latency or inertia of the pituitaryadrenocortical system. ACTH can be discharged at an accelerated rate within two minutes after application of stress to experimental animals (17), and the peripheral blood steroid level of man exhibits an increase within 15 minutes after the start of an intravenous infusion of ACTH (18). A significant increase in plasma corticosteroids has been reported to occur within 15 minutes after electroshock seizure in man (2).

We cannot conclude with certainty that the secretory activity of the adrenal cortex was increased during the longer exposures; we are only justified in saying that an imbalance between production and elimination resulted in an increase in the concentration of 17-hydoxycorticosterone in the plasma after two hours of exposure to adverse environmental conditions. Tyler, Schmidt, EikNes, Brown, and Samuels (19) have presented evidence which suggests that reduction in rate of steroid degradation by the liver is in part responsi- ble for the increase in peripheral blood steroid levels which occurs during and immediately following surgery. Regardless of the cause, increased rate of secretion or decreased rate of elimination, it is of some importance to find that certain individuals respond to heat plus hypoxia with an increased concentration of 17-hydroxycorticosterone in the plasma. Whether an increase of plasma corticosteroids above "nonstress" levels is of value to the individual in resisting the effects of heat plus hypoxia remains unanswered.

\section{SUMMARY}

Hypoxia (equivalent to that at 14,000 feet altitude), high environmental temperature $\left(50^{\circ} \mathrm{C}\right.$.), or hypoxia in combination with heat induced no detectable increase in the titer of ACTH in peripheral blood or in the concentration of plasma 17hydroxycorticosterone, or corticosterone-like steroids of healthy male subjects exposed for brief periods (not in excess of 45 minutes). In a second experiment, three of five subjects who experienced hypoxia of this degree in a heated decompression chamber exhibited significant increases in the concentration of peripheral plasma 17-hydroxycorticosterone after three hours of exposure. In a third experiment, five of eight subjects exhibited increases in plasma concentration of corticosteroid after two hours of exposure.

\section{REFERENCES}

1. Hale, H. B., Sydnor, K. I., and Sweat, M. L., Endocrine, cardiovascular, respiratory, and body temperature changes in man exposed to hypoxia combined with heat. Federation Proc., 1954, 13, 65.

2. Bliss, E. L., Migeon, C. J., Nelson, D. H., Samuels, L. T., and Branch, C. H. H., Influence of E.C.T. and insulin coma on level of adrenocortical steroids in peripheral circulation. Arch. Neurol. \& Psychiat., 1954, 72, 352.

3. Sandberg, A. A., Eik-Nes, K., Samuels, L. T., and Tyler, F. H., The effects of surgery on the blood levels and metabolism of 17-hydroxycorticosteroids in man. J. Clin. Invest., 1954, 33, 1509.

4. Bondy, P. K., and Altrock, J. R., Estimation of the rate of release of adrenal 17 -hydroxycorticosteroids in the human being by the venous catheter technique with a method for determining plasma 17 hydroxycordticosteroids. J. Clin. Invest., 1953, 32, 703.

5. Lewis, R. A., Thorn, G. W., Koepf, G. F., and Dorrance, $S$. S., The rôle of the adrenal cortex in acute anoxia. J. Clin. Invest., 1942, 21, 33. 
6. Frawley, T. F., Roche, M., Jenkins, D., and Thorn, G. W., The role of the pituitary adrenocortical system in the response to anoxia (abstract). J. Clin. Invest., 1951, 30, 638.

7. Thorn, G. W., Jenkins, D., and Laidlaw, J. C., The adrenal response to stress in man in Recent Progress in Hormone Research. New York, Academic Press Inc., 1953, vol. 8, p. 171.

8. Sweat, M. L., Adrenocorticosteroids in peripheral and adrenal venous blood of man. J. Clin. Endocrinol. \& Metab., 1955, 15, 1043.

9. Sydnor, K. L., and Sayers, G., A technic for determination of adrenocorticotrophin in blood. Proc. Soc. Exper. Biol. \& Med., 1952, 79, 432.

10. Sayers, M. A., Sayers, G., and Woodbury, L. A., The assay of adrenocorticotrophic hormone by the adrenal ascorbic acid depletion method. Endocrinology, 1948, 42, 379.

11. Hawk, P. H., Oser, B. L., and Summerson, W. H., Practical Physiological Chemistry. New York, Blakiston Co., 1954.

12. Craig, F. N., Ventilation requirements of an impermeable protective suit. The influence of temperature, humidity, and flow of ventilating air on the physiological strain. Medical Division Research Report No. 5, Army Chemical Center, Maryland, 1950.
13. Sydnor, K. L., Sayers, G., Brown, H., and Tyler, F. H., Preliminary studies on blood ACTH in man. J. Clin. Endocrinol. \& Metab., 1953, 13, 891.

14. Paris, J., Upson, M., Jr., Sprague, R. G., Salassa, R. M., and Albert, A., Corticotropic activity of human blood. J. Clin. Endocrinol. \& Metab., 1954, $14,597$.

15. Franksson, C., and Gemzell, C. A., Adrenocortical activity in the pre-operative period. J. Clin. Endocrinol. \& Metab., 1955, 15, 1069.

16. Nelson, D. H., and Samuels, L. T., A method for the determination of 17-hydroxycorticosteroids in blood: 17-hydroxycorticosterone in the peripheral circulation. J. Clin. Endocrinol. \& Metab., 1952, $12,519$.

17. Sydnor, K. L., and Sayers, G., Blood and pituitary ACTH in intact and adrenalectomized rats after stress. Endocrinology, 1954, 55, 621.

18. Bliss, E. L., Nelson, D. H., and Samuels, L. T., Effects of intravenous ACTH on blood levels of 17 hydroxycorticosteroids and circulating leukocytes. J. Clin. Endocrinol. \& Metab., 1954, 14, 423.

19. Tyler, F. H., Schmidt, C. D., Eik-Nes, K., Brown, H., and Samuels, L. T., The role of the liver and the adrenal in producing elevated plasma 17-hydroxycorticosteroid levels in surgery. J. Clin. Invest., 1954, 33, 1517. 